\title{
AC 2008-2031: "...A GOOD IMAGINATION AND A PILE OF JUNK"
}

\section{Shawn Jordan, Purdue Univeristy}

SHAWN JORDAN is a doctoral student in the School of Engineering Education at Purdue University, where he is studying geographically distributed design teams. He has appeared on many television shows with Rube Goldberg machines, including Jimmy Kimmel LIVE and Master of Champions on $\mathrm{ABC}$, and has won two National Rube Goldberg Machine Contest championships.

\section{Robin Adams, Purdue University}

Robin S. Adams is an Assistant Professor in the School of Engineering Education at Purdue University. She also led the Institute for Scholarship on Engineering Education (ISEE) as part of the Center for the Advancement of Engineering Education (CAEE). Dr. Adams received her PhD in Education, Leadership and Policy Studies from the University of Washington, a MS in Materials Science and Engineering from the University of Washington, and a BS in Mechanical Engineering from California Polytechnic State University, San Luis Obispo. Dr. Adams' research is concentrated on design cognition and learning (particularly iterative cycles in design), cross-disciplinary thinking, engineering epistemologies, building capacity in engineering education research, and strategies for connecting research and practice. 


\title{
"...A Good Imagination and a Pile of Junk"
}

\begin{abstract}
The engineering workplace is placing more emphasis on teamwork in interdisciplinary environments, out-of-the-box thinking, creative engineering, and brainstorming. These skills are taught to varying degrees in standard engineering curriculums, and often the most fruitful opportunities exist for students to learn in venues outside of the classroom.
\end{abstract}

This paper will show how building Rube Goldberg machines is a fantastic way for learners from various disciplines to get hands-on project experience in a team environment. Intense brainstorming and work sessions result in inventive and unique machines that are fascinating for both participants and spectators to watch. In addition, students have opportunities to apply the technical skills they have learned in the classroom in an application where creativity is king but reliability is key.

This paper takes the reader on a journey through the author's experiences leading a Rube Goldberg team through winning the national championship in 2006. This paper is the result of a deep iterative reflection, assisted by a collaborator in order to pull out the aspects of this experience that illuminate lessons related to design knowledge and learning. The aim of this paper is to identify important areas for future research and build a foundation for a future book intended to engage young learners in innovation and creative problem solving in a problem to product-focused environment. The experiences described in this paper will be particularly interesting to those looking to develop similar learning experiences for their students.

The machine the team built completed a task of individually shredding 5 sheets of $81 / 2$ " x 11 " $20 \mathrm{lb}$ paper into strips using a shredder over 215 steps. This paper will elucidate a successful design process including task determination, theme selection, module brainstorming, storyboard creation, and machine building. Artifacts of the process will be described, including an example of a module design where reliability became a problem that required multiple design iterations to thoroughly solve. Finally, a discussion of storyboarding as a way to promote creativity and innovation in design will be presented.

\section{Introduction and motivations}

The engineering workplace is changing to value teamwork in interdisciplinary environments, out-of-the-box thinking, creative engineering, and brainstorming. These attributes are highlighted in the recent Engineer of 2020 report $^{1}$. Similarly, industry trends are leading people studying innovation to look toward fostering environments for creativity and engineering ${ }^{2} 34$.

These skills are taught to varying degrees in standard engineering curricula, and often the most fruitful opportunities exist for students to learn in venues outside of the classroom. Within curricula, these opportunities typically appear in both freshman and capstone undergraduate 
design courses 56789 . Most are team-based, but their scope is limited to the particular course and provides students with a place where they can apply small amounts of their classroom knowledge.

Outside of the classroom, opportunities for students to explore interdisciplinary environments exist in a variety of competitions, such as FIRST Robotics, concrete canoe competitions, lunar module competitions, etc. This paper will show how building Rube Goldberg machines is a fantastic way for learners from various disciplines to get hands-on project experience in a team environment. Intense brainstorming and work sessions result in unique and inventive machines that are fascinating for both participants and spectators to watch. In addition, students learn to apply the technical skills they have learned in the classroom in an application where creativity is king but reliability is key.

The Rube Goldberg Machine Contest presents a fertile landscape for exploring these issues, but what is it really like? This paper attempts to capture a portion of the experience from the conception through completion of a Rube Goldberg machine (see Figure 1). It will begin with a brief history of Rube Goldberg the cartoonist, the Rube Goldberg Machine Contest, and the role that Rube Goldberg plays in the media and popular culture today. It will then go into detail on the design process used by the winning machine, with emphasis on drawing out interesting things learned from the experience. It will end with a brief discussion of future directions for research.

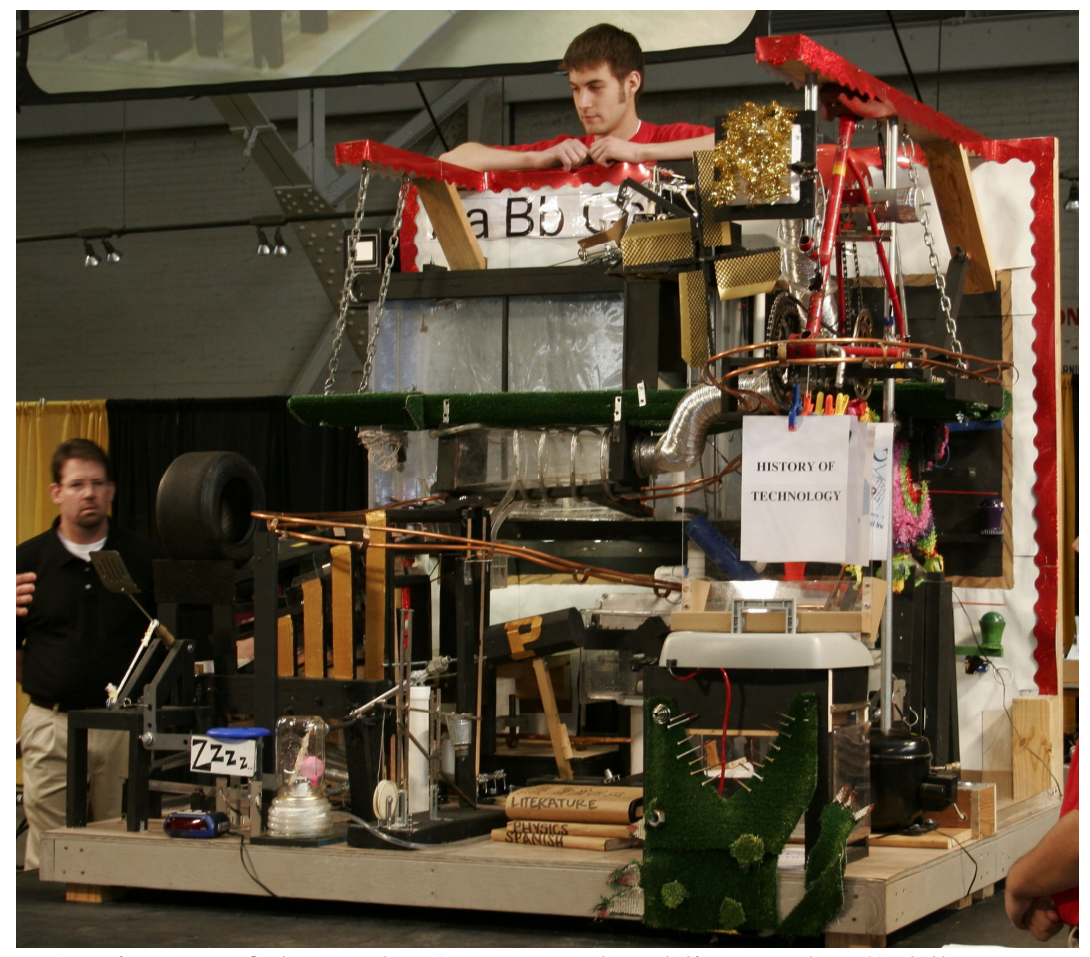

Figure 1: Picture of the author's paper-shredding Rube Goldberg machine 


\section{Background and context}

Reuben Lucius Goldberg (1883 - 1970) started his engineering career designing sewer systems. In 1914 after six months, he left engineering practice to become a cartoonist. His cartoons took a satirist point of view on technology, with his major underlying message being that technology misapplied often makes life unnecessarily complicated. According to Goldberg, his cartoons represent "a symbol of man's capacity for exerting maximum effort to achieve minimal results." He conveyed this message by drawing cartoons of fictional machines that completed simple tasks, such as changing a light bulb, in complex and roundabout ways. During his highly successful career, he won the Pulitzer Prize for his artistic works as a cartoonist, sculptor, and author $^{10}$.

Goldberg's cartoons appealed to many in engineering circles due to their comedic jabs at what engineers hold dear: optimal designs. This resulted in two engineering fraternities at Purdue University to start the Rube Goldberg Machine Contest in 1949. National competitions have been held annually at Purdue University since $1988^{11}$.

Rube Goldberg machines that have been built have been featured extensively in the media, resulting in audiences (including the author) becoming more interested in science, engineering, and technology. Contest-winning machines have appeared on Late Night with David Letterman, The Tonight Show with Jay Leno, Good Morning America, The Today Show, and Jimmy Kimmel LIVE.

The phrase "Rube Goldberg" is used as a hallmark of inefficiency outside the world of engineering. It is often used in reference to complex systems, including the healthcare industry ${ }^{12}$ and government ${ }^{13}$.

\section{Question in progress}

The author spent 8 years leading a Rube Goldberg team at Purdue University, during which he won numerous awards and two national championships, appeared on multiple nationallytelevised programs, opened a Rube exhibit at a museum, and did myriad presentations at a variety of venues to diverse audiences. These experiences have led to the author understanding the realm of Rube deeply, such that he is actively looking for ways to share these experiences so that others (particularly kids) can learn from them. Possibilities for the future include writing a book geared at helping kids get excited about science and technology, further exploring the possibilities for putting Rube machines in museums, continuing to share his excitement by way of conducting workshops for kids, teachers, parents, and other interested parties, and illuminating possible areas for future research.

While searching for a dissertation topic and after having recently retired from contest team leadership, the timing seems perfect for the author to deeply reflect on his experiences. This takes a form similar to what Schon ${ }^{14}$ describes, where retrospective accounts aid in understanding the Rube experience. Of particular interest to the author is what can be learned from the Rube experience about innovation and innovative thinking. The Rube process of innovation is unique, and could lead to interesting insights about how people think innovatively. 
Additionally, this paper seeks to provide a Rube roadmap for others to follow, and for the author to further his creative endeavors. In the process of identifying potential areas for future research, additional interesting questions might arise along the way. Immediate questions that come to mind include what the Rube process is and how it could be taught, how can the complex problem solving and design that occurs during the process be analyzed and characterized, and how does the Rube experience support creativity, innovation, and other creative endeavors.

\section{Results and discussion}

Many questions were illuminated during the author's extensive experiences in the Rube Goldberg machine world. Some of those questions were about the Rube design process that evolved, and how that process might be taught. Additional questions regarding the role of creativity and innovation in the Rube process and whether or not Rube can be used as a vehicle to aid in training students in those mindsets.

This section describes a retrospective and reflective account of the machine design process developed to build a successful Rube machine, and also discusses the role that reliability plays throughout the process. Many decisions are made during the process of building a Rube machine; only a few particularly interesting decisions are discussed in this paper.

\section{Machine design process}

Many factors play a role in stages of the machine design process. For example, Rube machines tend to be best designed as linear sequences of interconnected steps. Machines with nonlinear paths (multiple actions happening simultaneously) are both hard to follow and violate the spirit of Goldberg's cartoons. The major steps in the machine design process are task determination and interpretation, creating a theme and storyboard, brainstorming steps and mapping them to the storyboard, and finally implementing the steps.

\section{What is the problem? Task determination and interpretation}

Despite the appearance of having no purpose, machines that compete in the Rube Goldberg Machine Contest (RGMC) all have one thing in common: they complete the same task. The contest task is determined by the contest organizers and typically includes multiple facets in order to provide sufficient challenge for a college-level competition. The 2006 contest task was to "individually cut or shred into strips five sheets of $81 / 2$ " x 11" paper with a shredder in 20 or more steps" $"$.

It is up to each team to interpret the task statement in a "reasonable" way such that the contest judges will agree that they have completed the task. Discussions leading to an interpretation often start with an analysis of the task statement on a word-by-word basis. The author's team negotiated several major issues when framing how they would interpret the task.

The question of what a shredder is was discussed in detail. The obvious answer is the appliance that can be bought at an office supply store (and which had been donated to each team by a 
prominent maker of electric shredders), but the obvious answer is not always the best or most creative answer in the world of Rube Goldberg. Many ways to shred paper were discussed, including off-the-shelf paper shredders, blenders, pizza cutters, electric fans, razor blades, and were then narrowed down based on the additional task requirement that the paper be shredded into strips. In the end, these complicated ways of shredding paper were decided against in favor of using an off-the-shelf shredder.

Since the goal of Rube Goldberg machines is intentional technical obfuscation, this decision posed a strategic risk as being the "easy way out." The task statement stated that five sheets of paper must be shredded individually, creating opportunities for designing complexity into the system that transports paper into the shredder. This still presents a significant amount of risk, as a poorly designed transportation system could be prone to jamming. The contest scoring system favors less complex machines that work perfectly over more complex machines that require human intervention. In other words, the team has to navigate the tension between two competing perspectives on the nature of the task - being innovative and complex or accomplishing the task reliably.

This led to another major question of whether to shred all five sheets of paper individually throughout the machine run, or to shred them sequentially at the end of the machine run. Shredding throughout the machine run presents the challenging tradeoff of machine space versus technical complexity. Delivering five sheets of paper from five different parts of the machine to a common shredder presents many technical and reliability challenges, as well as conceptual challenges when it comes to maintaining visual linearity for the judges and spectators. Designing five separate shredders into the machine is both costly and space-consuming, limiting the number of other steps that can be put on the rule-governed 5' x 6' x 5' machine. A solution of shredding all five sheets of paper at the end of the machine run uses only one shredder, contains the paper transportation system to a particular part of the machine, and is a valid interpretation of the task statement.

This process highlights one of the interesting aspects of designing a Rube Goldberg machine: problem interpretation and reinterpretation. The decision to put the shredding module at the end of the machine created a new set of constraints for the designers of the module. While the electric shredder did the shredding, the paper transportation system needed to be technically complex and visually interesting. What is important is that while the task was common across all the teams competing, each team had to make design choices and selectively apply constraints, and those choices were a result of intra-team negotiation. These chosen constraints provided a basis for the design and a foundation for creating a feasible and reliable shredding module.

\section{What story is told? Themes and storyboards}

While not required by the contest rules, having a theme and storyboard governing a machine helps provide a cohesive story that both judges and spectators can more easily follow. For "outsiders" this serves to abstract the intentional complexity and make it easier for people to relate to the machine. For "insiders" (those creating the machine) the storyboard aids in selectively constraining the open-ended problem to provide a rationale for design decisions. 
The process of selecting a theme, which spanned over several meetings, began with brainstorming of ideas that were both relevant to the task and broad enough to support a wide variety of steps. This resulted in a large list of possibilities, including spies sending selfdestructing messages, recycling, a utilitarian approach to document management, and homework. After debate over the pros and cons of each option with respect to the task, the theme "The Rube Machine Ate My Homework" was chosen as the best option. While self-destructing spy messages are appealing to many, this represents the obvious choice for paper that needs to be destroyed and is not a prudent use of our creative talents. One of the intentional design constraints for theme selection is that it should be creative, as this up-front creative choice will promote more creative design choices throughout the machine. The chosen theme appeals to a wide variety of audiences in that the machine itself represents an excuse, and also exemplifies the kind of satirical technological humor Goldberg was famous for. Instead of a dog eating your homework, a common stereotypical excuse, the Rube machine is eating your homework in a very complicated way.

Just as cartoons (including Goldberg's) and movies rely on storyboards to support their plots, Rube machines have much to benefit from using the same technique. Upon deciding the theme, a storyboard was written to fill out the story that would be told through the complex interconnections of junk. The author's team chose to tell the story of a fictitious character's journey through a day of school, starting with hitting the snooze button on his alarm clock and ending with his history paper being shredded minutes before it was to be turned in. This storyline provided an easy-to-grasp concept that was easy to map a wide variety of steps to, planting the seeds for creativity around each set of steps as part of an unfolding story line.

One interesting point to note is that themes and storyboards are self-imposed artificial design constraints, and are not dictated in any way by the rules of the competition. However, the problem of creating a Rube Goldberg machine spans beyond the simple engineering challenges of building steps; it also involves creating a machine that people understand. Themes and storyboards provide a way of managing the comprehension challenge by marketing the complexity in an appealing way. Additionally, artificial design constraints provide a framework for reasoning through problems encountered during the implementation stage of a Rube machine. Since engineering is based on logical reasoning, manipulating these frameworks carefully can drastically affect the creativity involved in the solution.

\section{What actually happens in a Rube machine? Brainstorming steps}

In parallel with selecting a theme and writing a storyboard, early meetings were devoted to brainstorming innovative ideas for steps. Many of these ideas came from classes, museums, cartoons and television, interesting objects from the real world, and even late-night shopping experiences. Thinking of how different kinds of energy, such as mechanical, chemical, or electrical, could be transformed sometimes resulted in new ideas being generated. Some steps stemmed from the development of a particular technology over time. For instance, the author's machines often featured two-rail roller coasters for billiard balls. Each year, the roller coaster technology would be pushed to further exploit the limits of the technology. 
Upon accumulating a list of potential steps and writing a viable theme and storyboard, steps are mapped to the storyboard. Not all steps will be used, as this process is much like putting together a jigsaw puzzle with extra pieces. The goal is to find the pieces that best fit together, saving the rest for future puzzles.

\section{How is a Rube machine realized? Implementation}

In all, 215 steps organized into 16 major modules were designed and constructed. This stage typically results in iterative redesigns and re-examination of the problem statement determined at the beginning of the design process.

\section{How is a module actually designed? Example}

Part of designing an exciting Rube machine is making it both a visual and an auditory work of art. Keeping this goal in mind, the author's team decided to attempt to play the Purdue fight song by individually striking pitched glockenspiel bars. Within the context of the theme, this song represented a band class, and the finished product had many similarities to a player piano.

First, practical limits for the design were set. It was decided by an informal poll of interested parties that playing the first six notes of the song was the minimum for spectators to recognize the song, meaning that the machine would need to hit six individual bars. Other than keeping the step generally compact (as all modules typically are), no specific size constraints were levied due to its construction during the early stages of the contest year.

Second, ways to strike the bars were discussed. The two major options were dropping metal balls on the bars and hitting the bars with mallets or hammers (like a piano). When the artificial constraints of sound quality and ease of construction were employed, it was decided that dropping metal balls on the bars was the better option.

Next, a method to create the different note intervals was needed. This perceptual requirement meant that balls would need to be dropped in sequence at different, reasonably repeatable points in time, dictating the need for fixed time delays. The two major options discussed for achieving this goal were dropping the ball from different heights or letting the ball roll down ramps of different lengths to create a delay. Calculations involving the acceleration of the ball due to gravity eliminated dropping the ball as a viable option, as the 5' height limit for the machine did not provide for sufficient time delays between notes.

Once the major design decisions had been made, a prototype was constructed. Many construction challenges still occurred during this stage, such as creating reliable ball release mechanisms and controlling erratic ball movements. These problems were addressed in a second iteration of the step, and it went on to become one of the most memorable steps in the machine. 


\section{What is REALLY the problem? Reliability}

Reliability is a key concern in Rube machines. As is often the case in real life, a machine with creative ideas that does not fulfill its promises of working will lose to a less creative machine that works perfectly. This means that designing for reliability must be considered throughout the creative and construction processes. The author's team followed several rules to improve reliability.

First, the design and build stages were executed simultaneously, an idea borrowed from the world of software engineering ${ }^{16}$. Extreme Programming, a method popularized by Microsoft, attempts to address fast-changing user requirements that typically occur during a project by iterating between design and prototyping stages, rather than designing an entire product first and then building it. Since Rube machines are typically dynamic artistic creations that undergo many changes during their cycle of development due to practical realizations, this model lends itself nicely to the Rube environment.

Second, the mantra "if it doesn't work, fix it or cut it" was used in order to guide the team and bring them back to the reality that the machine needed to work in the end. This often led to multiple iterations of step designs and implementations, but as the contest time grew closer several steps were cut due to both space constraints and reliability concerns.

Finally, testing played an integral role to improving reliability. The mantra "test until it works, and then test again" was followed, and resulted in uncovering many issues that were resolved before the competition.

One example of reliability and step iteration occurred during the construction phase of an earlier Rube machine. The step encountering problems dropped batteries quickly out of a rolling cart and into the back of a flashlight. However, through repeated testing it was determined that $20 \%$ of the times the step failed due to one of the two batteries ending up in the flashlight backwards. Visual observation of the system uncovered no reason why the failure was occurring, so a video camera was employed to capture evidence of the failures. Upon inspection of the video of a failure frame-by-frame, it was discovered that sometimes a battery would come out of the cart too early, resulting in enough time in the air for the battery to rotate 180 degrees before landing in the flashlight. Upon identification of the source of the problem, a stationary wall was added at the flashlight loading funnel to prevent batteries from exiting the cart early, and the problem was solved.

\section{Future steps}

Many lessons were learned during this illuminative reflection process, including the role a strong process plays in creating a successful environment for innovation. Several researchable questions arose from the study.

- How do different interpretations of a problem change the course that a design takes?

- How can reliability in design be taught?

- How can artificial design constraints be used to stimulate creativity? 
The next step is for the author to continue reflecting on his Rube experiences as he works toward research in the innovation space. Additionally, the K-12 community can benefit from the lessons to be learned from Rube. The author recently completed developing and pilot-testing a Rube Goldberg machine-building curriculum for $5^{\text {th }}$ and $6^{\text {th }}$ graders as part of a Saturday enrichment program. A book geared toward younger kids can help inspire invention and innovation at a young age.

\section{Conclusions}

This paper described how innovative solutions were achieved through a creative design process centered on building Rube Goldberg machines. The author's experiences and lessons learned while participating in the Rube Goldberg Machine Contest and building a machine were described. Building these machines allows learners to get hands-on project experience in a team environment, often while working with people from multiple disciplines. These informal learning experiences build the participants' teamwork skills that can then be applied to postcollegiate endeavors.

"To invent, you need a good imagination and a pile of junk." -Albert Einstein

\section{Bibliography}

1 National Academy of Engineering. (2004). The engineer of 2020 : visions of engineering in the new century. Washington, DC: National Academies Press.

2 Johansson, F. (2004). The Medici effect : breakthrough insights at the intersection of ideas, concepts, and cultures. Boston, Mass.: Harvard Business School Press.

3 Kelley, T., \& Littman, J. (2001). The art of innovation : lessons in creativity from IDEO, America's leading design firm (1st ed.). New York: Currency/Doubleday.

4 Nadler, G., \& Hibino, S. o. o. (1994). Breakthrough thinking (Rev. 2nd ed.). Rocklin, CA: Prima Pub.

5 Atman, C. J., Cardella, M. E., Turns, J., \& Adams, R. (2005). Comparing freshman and senior engineering design processes: an in-depth follow-up study. Design Studies, 26(4), 325-357.

6 Sheppard, S. and R. Jenison (1997a). "Examples of Freshman Design Education." International Journal of Engineering Education 13(4): 248-261.

7 Sheppard, S. and R. Jenison (1997b). "Freshman Engineering Design Experiences: An Organizational Framework." International Journal of Engineering Education 13(3): 190-197.

8 Todd, R. H., Magleby, S. P., Sorensen, D. D., Swan, B. R., and D. K. Anthony (1995). "A survey of capstone engineering courses in North America." Journal of Engineering Education 84 (2), 165-174. 
9 Turns, J., R. S. Adams, J. Martin, M. Cardella, S. Mosborg \& C. J. Atman (2006). "Tackling the Research-toPractice Challenge in Engineering Design Education: Insights from a User-Centered Design Perspective,"

International Journal of Engineering Education (invited paper).

10 Wolfe, M. F., \& Goldberg, R. (2000). Rube Goldberg : inventions. New York: Simon \& Schuster.

11 Machine Contest History. Retrieved 1/12/07, from http://www.rubegoldberg.com/machineContestHistory.php

12 Thompson, R. (2006). Competition the Cure for Healthcare. Retrieved 1/12/07, from

http://hbswk.hbs.edu/item/5452.html

13 Drobny, S. (2006). The Rube Goldberg Solution to Iraq. Retrieved 1/12/07, from

http://www.huffingtonpost.com/sheldon-drobny/the-rube-goldberg-solutio_b_35084.html

14 Schön, D. A. (1983). The reflective practitioner : how professionals think in action. New York: Basic Books.

15 Rube Goldberg Contest at Purdue. (2006). Retrieved 1/12/07, from

http://news.uns.purdue.edu/UNS/rube/rube.index.html

16 Beck, K., \& Andres, C. (2004). Extreme programming explained : embrace change (2nd ed.). Boston, MA:

Addison-Wesley. 